\title{
FORMA E MATÉRIA NA SINTAXE ROSIANA
}

\author{
João Batista Santiago Sobrinho*
}

RESUMO:

Pretendo demonstrar que os conceitos de Gaston Bachelard, forma $e$ matéria contribuem para a compreensão do temperamento literârio do Escritor Guimarães Rosa e seus múltiplos narradores.

PALAVRAS-CHAVE: Gaston Bachelard, João Guimarães Rosa, ägua.

$$
\begin{array}{r}
\text { Ouvi estas águas } \\
\text { de repente sempre } \\
\text { etc. } \\
\text { João Guimarães Rosa }
\end{array}
$$

Aos estudos das imagens da água presentes na obra de João Guimarães Rosa posso encetar alguns fatores cuja relevância científica poderia ser questionada, não fosse o apoio teórico especulativo do filósofo e ensaísta francês Gaston Bachelard. Antes de lê-10 minha intuição hídrica comunicava-me que, para além das searas acadêmicas, as águas de minha aventura pessoal certamente contribuíram para o avistar e, posteriormente, o desvelar das águas rosianas. Achava que tal afirmação caberia mais ao universo poético e menos ao campo epistemológico. Felizmente salvou-me o filósofo. Pude, sem maiores escrúpulos, incorporar meus rios, Rio Grande (o da infância, de águas claras) e o Rio Pomba (o da adolescência e maturidade, de águas escuras), às minhas especulações sobre a matéria água, às águas rosianas. Por intermédio do ensaio de Bachelard, A água e os sonhos, compreendi melhor a dinâmica das águas:

0 indivíduo não é a soma de suas impressões gerais, é a soma de suas impressões singulares. Assim se criam em nós os mistérios familiares, que se designam em raros símbolos. Foi perto da água e de suas flores que melhor compreendi ser o devaneio um universo em emanação, um alento odorante que se

|* Mestre em Letras: Estudos Literários (Área de concentração: Literatura Brasileira), 2003. 


\section{EMTESE}

Belo Horizonte, v. 8, p. I-243, dez. 2004

evola das coisas pela mediação de um sonhador. Se quero estudar a vida das imagens da água, preciso, portanto, devolver ao rio e as fontes de minha terra seu papel principal (Bachelard, 1998:02).

Creio que desenvolvi, considerando uma longa vivência com a natureza e as águas em minha vida, inconscientemente, uma sensibilidade para a água. Assim, pude, aliado à teoria e à crítica literária, percebê-la e rastreá-la na forma, e aprofundá-la como matéria, sob a escrita rosiana.

Bachelard, no início de seu livro $A$ água e os sonhos, destaca dois tipos de imaginação, uma formal e outra material. Investiguei na narrativa rosiana, mais especificamente o romance Grande sertão: veredas, principalmente, aquilo que está sob as imagens da forma, no intuito de desvelar as imagens da matéria água. Bachelard desenvolve sua teoria material por intermédio dos pré-socráticos, cujas forças imaginantes vinham sempre temperadas por um dos elementos, terra, água, fogo e ar. Para Tales, o elemento primordial era a água; para Heráclito, o fogo. Segundo Bachelard há obras em que esses dois tipos de imaginação trabalham juntos, e creio ser este o caso da obra rosiana, na qual forma e matéria convergem, em vários momentos, numa só substância - a água - capaz de ser percebida nos vocábulos e significantes inúmeros que saltam abundantes como peixes na piracema. Veja-se, como exemplo, a expressão "Matéria vertente", forjada pelo narrador protagonista do romance Grande Sertão: veredas, Riobaldo, quando este questiona suas incursões nos recantos da memória:

Eu queria decifrar as coisas que são importantes. E estou contando não é a vida de sertanejo, seja se for jagunço, mas a matéria vertente. Queria entender do medo e da coragem e da gã que empurra a gente para fazer tantos atos, dar corpo ao suceder (Rosa, 1985:93).

Riobaldo deseja lembrar-se, mas o sertão é "vertente", se liquefaz o tempo todo. Muitos lugares que marcaram sua vida, não existem mais, como, por exemplo, a paradisíaca e inesquecível "Guararavacã do Guaicuí", que virou "Caixeirópolis": 0 senhor tome nota deste nome. Mas, não tem mais, não encontra de derradeiro, ali se chama é Caixeirópolis (Rosa, 1985:270). 0 sertão que Riobaldo quer é tempo vertido, águas passadas, memória, já não há, como o rio é sempre outro. (Nunes, 1983). Mais explicitamente, percebe-se a matéria e a forma tensionadas no nome do próprio romance, que reúne o seco e o úmido, o sertão e a vereda, a terra 
e a água. Mescla que redundará por toda a narrativa de Riobaldo, cujo próprio nome também encarna a matéria líquida, "Rio" e "baldo", que se traduz, na fala do sertanejo, por "bardo", poeta, aquele que investiga, que tem no tempo, sua matéria. Ainda com referência ao sertão, ele nos remete, sobremaneira, ao deserto, à areia, e às veredas, às águas. A areia que, em análise simbólica mais profunda, confundese com a água. Guimarães Rosa, nas cartas que escreve ao seu tradutor italiano, Edoardo Bizzarri, afirma que as veredas são, além de caminho, nódulos hídricos do sertão. E, tirante o São Francisco, confirma Riobaldo, "o resto pequeno é vereda" (Rosa, 1985:68).

Especulando sobre a forma e a matéria da narrativa rosiana, a crítica literária, ao debruçar-se sobre o texto rosiano, se expressa por qualificadores líquidos. Talvez porque a água "proporciona um tipo de sintaxe" (Bachelard, 1998:13). Para referir-se à natureza peculiar da sintaxe rosiana, a crítica literária lança mão de expressões como jorro, fluxo ou "fronteiras movediças" (Finazzi-Agro, 2001:27); "uma textura, que [...] flui ao correr da leitura" (Vargas, 1957:19); um "estilo que dissolve a acepção clássica em que o estilo inventa o texto?" (Hansen, 2000:23); "universo fluido de sentidos figurados" (Rosenfield, [s.d]:28); ou ainda, a "estrutura meândrica da narrativa" (Nunes, 1983:18), que proliferam sempre que se tenta dar conta da linguagem desse escritor. Para Scarpelli, Guimarães Rosa situa-se "entre duas águas. Desdobra-se entre o público e o privado, entre o mundo e o sertão" (Scarpe11i, 2000:102). Portanto, são vários os fatores que corroboram minha afirmação de que Guimarães Rosa encontrou uma maneira de tensionar forma e matéria em sua arte de narrar. Em carta ao amigo João Condé, a água, como metáfora, sobressai-se quando Guimarães Rosa refere-se à gestação do livro Sagarana:

Assim, pois, em 1937 - quando chegou a hora de "Sagarana" ter de ser escrito, pensei muito. Num barquinho, que viria descendo o rio e passaria ao alcance de minhas mãos, e eu ia poder colocar o que quisesse. Principalmente, nele poderia embarcar, inteira, no momento, a minha concepção-do-mundo (Rosa, V.G., 1999:377).

Mais abaixo, na mesma carta, Guimarães Rosa utiliza-se de uma frase de André Maurois, metaforizando uma escrita sem limitações, sem imposições de estilos, e usa de outra imagem de água, "um rio sem margens é o ideal do peixe" (Rosa, V.G. 1999:377). Tempos depois, em entrevista concedida a Günter Lorenz, Guimarães Rosa 


\section{EMTESE}

Belo Horizonte, v. 8, p. I-243, dez. 2004

compara os rios às almas dos homens: "os rios são profundos como a alma do homem. $\mathrm{Na}$ superfície são muito vivazes e claros, mas nas profundezas são tranqüilos e escuros como os sofrimentos dos homens" (Rosa, 1994:37). Desde o início, a presença do rio, como a da água, freqüenta o imaginário do autor.

Na narrativa rosiana, o aforismo de Heráclito, "não entramos duas vezes no mesmo rio", surge todo o tempo com um vigor extraordinário. Riobaldo irá reformulá-10 em alguns momentos, como, por exemplo, em: "Cheguei a encarar a água, - Rio das Velhas passando seu muito, um rio é sempre sem antiguidade" (Rosa, 1985:136). É sempre velho e novo, porque são sempre outras suas águas.

Na busca da matéria do sertão, adentrei aos rios rosianos para dinamizar as águas, referência mais profunda, chegando, finalmente, à matéria água. As presenças dos rios, riachinhos, poços, lagoas, veredas, orvalhos, assim como cavalos, vacas, bois, touros, luas, sapos, na obra rosiana, passam a comportar um oceano simbólico, em que a imagem da água, como matéria, supera substancialmente os aspectos toponímicos. No sentido de dinamizar ainda mais o complexo hídrico rosiano, o qual dá-nos mais subsídio para corroborar o conceito de matéria, um outro conceito de Bachelard torna-se imprescindível, o de "ressoadores". Através dos "ressoadores", a água, como matéria do sertão, fica devidamente dinamizada, cheia "de ecos" (Bachelard, 2001:5). Portanto, os ressoadores funcionam como ecos da matéria água, dando maior densidade e dinamicidade à mesma. Comportam esses ecos das águas imagens recorrentes na obra rosiana: da lua, do sapo, da vaca, do touro, do cavalo (Durand, 2001). A simbologia que os envolve, por suas relações com a água, ressoa e aflui harmonicamente para o "mar de territórios", metáfora usada por Riobaldo para referir-se ao sertão, e contribui para uma espécie de cosmogonia hídrica do sertão, como convergência, em última instância, de forma e matéria, no universo da obra rosiana.

ABSTRACT :

I intend to demonstrate that Gaston Bachelard's concepts of shape and matter help us to understand the literary temperament of the writer Guimarães Rosa and his multiple narrators.

KEY WORDS: Gaston Bachelard, João Guimarães Rosa, water. 
BACHELARD, Gaston. A água e os sonhos. São Paulo: Martins Fontes, 1998.

BACHELARD, Gaston. 0 ar e os sonhos. São Paulo: Martins Fontes, 2001.

DURAND, Gilbert. As estruturas antropológicas do imaginário. São Paulo: Martins Fontes, 2001.

FINAZZI-AGRO, Etore. Um lugar do tamanho do mundo. Belo Horizonte: UFMG, 2001.

HANSEN, João Adolfo. o 0: a ficção da literatura em Grande sertão: veredas. São Paulo: Hedra, 2000.

NUNES, Benedito. "A matéria vertente". In: Seminário de Ficção Mineira: de Guimarães Rosa aos nossos dias, 2, 1982, Belo Horizonte. Anais... Belo Horizonte: Conselho Estadual de Cultura de Minas Gerias, 1983.

ROSA, João Guimarães. Grande sertão: veredas. Rio de Janeiro: Nova Fronteira, 1985.

ROSA, João Guimarães. Ficção completa. Rio de Janeiro: Nova Aguilar, 1994.

ROSA, Vilma Guimarães. Relembramentos: João Guimarães Rosa, meu pai. Rio de Janeiro: Nova Fronteira, 1999.

ROSENFIELD, Kathrin, H. Os descaminhos do demo. São Paulo: Imago, 1993.

SANTIAGO SOBRINHO, João Batista. As imagens de água no romance Grande sertão: veredas, de João Guimarães Rosa. Belo Horizonte: Fale/ UFMG, 2003. (Dissertação de Mestrado).

SCARPELLI, Marli de 0liveira Fantini. Fronteiras do falso: a poética migrante de Guimarães Rosa. Belo Horizonte: Fale/UFMG, 2000. (Tese de Doutorado).

VARGAS, Milton. Visão e descrição. Diálogo revista de cultura, 8. São Paulo: Sociedade Cultural Nova Crítica, 1957. 